\title{
Backwash Effect of Language Test on English Language Teaching
}

\author{
Renfeng Wang \\ Department of English \\ Yantai Nanshan University \\ Longkou, Shandong, Cnina 265700
}

\begin{abstract}
Language test is an important means of measuring the effects and improving the quality of foreign language teaching. Testing washback effect on foreign language teaching increasingly highlights. The article takes college English teaching as an example and discusses the backwash effect of language test on English language teaching.
\end{abstract}

Keywords-language test; English language teaching; backwash effect

\section{INTRODUCTION}

Test forms an important part of teaching. The contents and forms of test will have a great feedback effect on both teaching and learning, namely backwash effect. Hughes believes that te aching and test is forms a relationship of "partnership" and the two aspects are interrelated and affects each other. On the one hand, test not only serves the teaching, but also influences teac hing contents and teaching methods directly, playing a certain backwash effect on teaching, as positive backwash effect may promote teaching development, yet the negative backwash effe ct may impact or mislead teaching.

\section{Problems EXIST IN LANGUAGE TeST}

Language test includes achievement test and level test. This paper mainly discusses the achievement test. At present, college English tests in most colleges and universities in our country mainly refer to the final test and CET tests. The final English test focuses on the test on language knowledge, of which the questions are fixed and lack of flexibility; in the teaching process, it is often difficult for teachers to mobilize students' learning enthusiasm in the classroom, and students learn the knowledge passively, lack of learning initiative and enthusiasm of participation in classroom communication, creating a large number of students of high score but low ability with poor actual application ability which can't reflect students' actual language application ability, and deviates from the cultivation goal and cultivation feature of language teaching.

As a method of measuring students' level, the CET Band 4 will inevitably evaluate the school's teaching effect and student's learning outcomes. After the end of the test each year, the pass rate will be calculated naturally, which often results in the comparison between various colleges and universities. In order to cope with the test, some colleges even finish their course in advance, and take exercises for the exams. There is no denying the fact that simulation training will help students to familiar with the questions, and improve their ability to cope with test. But such exam-oriented teaching has disturbed the normal teaching order, teachers teach less of the compulsory college English textbook and students use less of the textbook, some students even only work on the questions training about CET tests. Such attitudes and practices will make students hard to lay a solid foundation. Even if though they have passed the CET tests, they cannot use it skillfully in future work, losing the significance.

\section{BACKWASH EFFECT OF LANGUAGE TEST ON ENGLISH TEACHING}

The importance of backwash effect on English teaching by language test has drawn great attention of the linguists. Alderson and Wall are the pioneers in the field of backwash research. They proposed backwash effect hypothesis and pointed out a way of thinking for backwash effect theory research from the perspective of students - teachers and teaching - learning, laying a certain foundation for the later researchers to conduct empirical research in this field.

\section{A. Methods to Improve Positive Backwash Effect}

The backwash effect of test can be positive and negative (Hughes). One of the purposes to research backwash effect is to reduce negative backwash effect and improve the positive backwash effect. Take the college English final test as an example, if the fixed question pattern is adopted for a long term, students will guess the questions objectively. And in the teaching process, teachers will be inevitably partial to the exam-oriented teaching. Such test will certainly bring bad teaching effects. Hughes (1989:44-46) has put forward seven suggestions for improving positive backwash effects of test: ability shall be cultivated through test; the test range shall be wide without predictability; use the test practically and directly; use the scale reference; achievement test shall be based on the teaching goal; make students and teachers understand the test; provide assistance to teachers when necessary. Most of these suggestions are relating to test validity, because test validity is closely related to backwash effect. The purpose of testing is to serve teaching ultimately. As a teacher, I put forward some of my own suggestions combining my own teaching practice and 
thinking, in order to make the test generate positive backwash effect on teaching:

1) Be strict with the students: Strengthen check on attendance at ordinary times. If the students who frequently absence from class, but get exam scope and question patterns before the test, and study hardly before test, then participate in the test and pass it, then we can imagine how will he treat the future courses. As a result, the student whose absence has exceed one third of this course's total class hours within one semester shall be prohibit from participating in the exam. "Teaching shall be responsible for the loose discipline", only the responsible teachers will be strict with students. And only the strict teachers will make efforts to design a qualified test paper.

2) Specify test objectives: Any test questions shall reflect the understanding of the setter of an exam paper toward teaching focus and the law of language learning. The development trend of test is "transformation from knowledgebased to skill-based, and transformation form rote memory to practical application". In the teaching process, teachers shall gradually get rid of the restriction of exam-oriented education, and conduct foreign language teaching based on their respective teaching outline, pay attention to the training and application of language ability. Thus the practical significance of language learning will not be deviated; foreign language teachers shall master the basic testing theory and method, and design different test questions according to different teaching goals; in the teaching process, teachers shall pay attention to the difference between mother tongue and target language, master the changes in students' transformation of native language into target language. Each unit of the course of "Practical English 1" taught by me in this semester has a clear theme, closing to our real life, such as express gratitude, congratulations, and invitations and so on. In the process of teaching the dialogue link, I choose to make conduct situation dialogues on spot, to achieve the effect of playing whiling learning as well as remembering while learning, enabling the students to learn in the pleasant class link. For the part of text, I add the part of grammar and translation in it, so that the students can firmly grasp the basic knowledge. For the listening part, not only the hearing is tested, but also the ability of shorthand is practiced. Then make them organize the short article that has been heard using their own words to repeat, achieving the effect of combining hearing with speaking.

3) Test questions variability: For most of the institutions of higher learning, English learning will last four semesters. If the test questions remain the same every semester, students can basically deduce the test questions of the rest three semesters after taking the examination of the first semester, this will inevitably lead to two kinds of results: one is that students will pay close attention to the exam questions in the learning process, and get high marks in the final exam; the other is that part of the students will not listen carefully in class or even skip the class, and study hardly before the test just for passing the exam. Such result has deviated from the training objectives of school. Therefore, the scope of questions in final test should not be too narrow, and the question pattern shall not be fixed. The questions shall not only be able to test the students' mastering of language knowledge, but also be able to test students' practical ability of using language. Our traditional teaching often pays attention to the mastering of language knowledge, while ignoring the practical application of knowledge, which does not conform to the basic function of language as a communication tool, and will be bound to produce the students with high score and poor ability. As a result, the students' final test scores can be made of the performance at ordinary times (attendance, class performance, homework) + midterm performance (speaking/listening/writing) + final performance (test paper score). Targeted changes can be made each semester for the final exam. Thus, it will be of freshness and challenging for the students.

\section{B. Reduce the Negative Backwash Effect on English Teaching by English Test}

Prodromou (1995) argues that negative backwash effect on English teaching by English test can be divided into overt backwash effect and covert backwash effect. Overt backwash effect refers to the direct and obvious exam-oriented teaching, for instance, students have to do a lot of so-called actual test questions, simulated test questions and after-school exercises related to the examination, absolutizing the test scores, changing the lively language teaching into the boring examination skills training, hindering the improvement of students' language application ability, and resulting in the phenomenon of "Dumb English", which deviate from the fundamental purpose of language teaching; while the covert backwash effect refers to the deep and not easily perceived influence on teaching. This influence is deeply and subtly rooted in teaching and education. And it will result in the students' lose of personality and initiative toward learning, and they will always be afraid to make mistakes, to fail and be criticized in the classroom. Similarly, teachers will worry about students' test scores, and may encourage students to gain high marks using all possible methods, and in the end, it will inevitably lead to that teach for coping test, and the classroom will become the examination room.

For this reason, Kellaghan \& Greaney have put forward 11 suggestions for improvement of exam and reduction of negative effect on teaching by test: the examination shall reflect all but not part of the course connotation; the examination shall involve the advanced cognitive skills to promote teaching; the skills to be tested shall not only be limited to complete school learning tasks, but also shall include the external task skills; the test form shall be diversified, including written and oral English, listening and practical test; the impact by factors other than teaching shall be considered when evaluating the examination results and rankings; timely feedback to the school about students' test scores and problems; conduct predictive validity research on public examination; improve the professional level of test institutions, especially the question setting level; examination 
committee shall conduct research on the influence on teaching by test; testing institution shall develop close cooperation with curriculum development agencies and education management; simplify local examination network, and conduct related communication.

Therefore, to reduce the negative backwash effect, discussion simply from the perspective of test is not enough, it shall also be discussed from the following several aspects:

- Transform the teaching concept. Transform from "teacher-centered" to "student-centered", and transform from the knowledge-based teaching to skillbased teaching. In college English teaching, a variety of ways are adopted to cultivate the students' learning initiative and innovation spirit and inspire students' thinking, rendering them the comprehensive development. In addition, in the teaching process consisted of "teaching" and "learning", teachers should pay attention to inspire, and students shall take initiative to participate in. The success of teaching not only depends on the teachers' "inspiration", at the same time, it can reflect students' active thinking. As a result, the heuristic teaching reflects the democratic equal relationship between teachers and students. Only the tacit understanding of interaction between teachers and students as well as the resonance between teaching and learning can be achieved can it be called the ideal teaching. While performing heuristic teaching, teachers must consider problems from the perspective of students, analyze students' interest, seize the difficulties and key points of knowledge, and then explain and guide from the easy to difficult ones, inspire students' thinking in a variety of means, and achieve the effect of students' enlightenment.

- Reform the evaluation methods. Teaching evaluation is an important part of university teaching. The comprehensive and objective evaluation system is very important to realize the goal of curriculum. Scientific and accurate assessment system is not only the important basis for teachers to acquire teaching feedback information, improve the teaching management and to ensure the teaching quality, but also the effective means for students to adjust learning strategies, improve learning methods and enhance the learning efficiency. To evaluate student's English level simply by the final examination scores is not enough scientific and comprehensive, and is not easy to arouse students' enthusiasm to participate in classroom activities. So there exists quite lot of drawbacks, causing some students only pay attention to the final exam, and ignore the usual classroom learning. The indifference to accumulation process of language learning makes it difficult to have a substantial increase in the actual application ability. At present, the new type of CET test Band 4 has aroused the attention of the teachers and students, and won the high praise. The new CET tests can be able to better service the new target of college English teaching, namely, the transformation from language knowledge to application skills of language. The new CET tests can measure students' actual level of English application from different angles, different channels and different levels. The implementation of CET tests can effectively reverse the situation of teaching and learning for examinations, and promote the communication-oriented college English teaching. Most college English teachers and students think that the new CET tests have generated more positive backwash effect, and have promoted the college English teaching reform.

\section{CONCLUSION}

As an independent discipline, language test can be used for measuring learning effect and checking the teaching situation when it is applied to language teaching. Both teaching and learning must be examined regularly by teaching goal and teaching quality via language test. Language test can determine effective teaching measures and methods, and find out the deficiency of teaching, provide advice for teaching improvement. Language teaching shall cultivate students' ability of effective communication with the target language, and language test shall pay attention to measuring of students' ability in this aspect, so that the test may become the effective way to achieve the purpose of classroom teaching. We shall specify the relationship between testing and teaching, pay attention to the backwash effect on language teaching by language test, to make language test serve language teaching.

\section{REFERENCES}

[1] Huang Dayong. Research Review of Language Test's Backwash Effect [ J] . Foreign Language Teaching and Research (foreign language bimonthly), 2002(4).

[2] Liu Runqing, Dai Manchun. Foreign Language Teaching Reform in Chinese Universities [M] Beijing: Foreign Language Teaching and Research Press, 20041

[3] Yin Chao. Journal of Changchun Normal College, 2009 (1)

[4] Zhang Huajun, Wan Ling. China Education Innovation Herald, 2009 No. 22

[5] Wei Chunya. Impact on English Teaching by Test's Negative Backwash Effect $[\mathrm{J}]$ Journal of Yangling Vocational and Technical College. No. 3(2), June 2004.

[6] Cai Zhenqun. Backwash Effect on Teaching by English Test: Foreign Language Research [J]. 2011(4), 106. 